\title{
Wir erfüllen Wünsche
}

_ Manche lieben Fakten, andere brauchen Bilder und mögen es möglichst anschaulich. physiopraxis verbindet beides. Sie bietet beispielsweise zweimal im Jahr die physiografik zum Aufklappen oder Heraustrennen und Aufhängen. In dieser Ausgabe widmet sie sich dem Thema Hüft-TEP (๑ S. 48). Der Einsatz eines künstlichen Hüftgelenks gehört in Deutschland zu den Top Ten der häufigsten Operationen. Die Medizintechnik hat sich inzwischen so entwickelt, dass Endoprothesen optimal auf die individuelle Situation des Patienten abgestimmt werden können. Die physiografik spannt den Bogen von der ersten Prothese aus Elfenbein bis zum heutigen Baukastensystem moderner Endoprothetik.

- Wir sind gespannt, wie Ihnen die physiografik

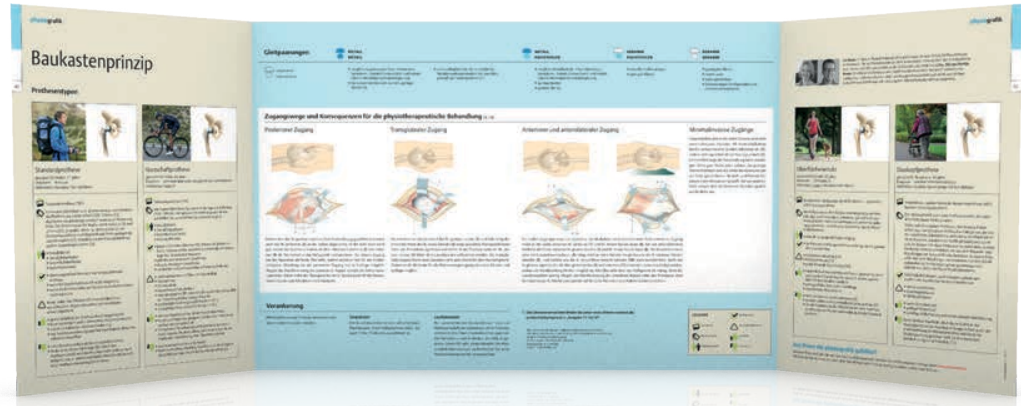
gefällt, und laden Sie ein, an unserer Umfrage teilzunehmen. Vielleicht finden Sie ja trotz Weihnachtstrubel Zeit dafür. Sie haben einen Themenwunsch für die physiografik? Auch das können Sie uns auf diesem Weg mitteilen.

_ Vielen Dank für Ihr Feedback. Wir wünschen Ihnen entspannte Weihnachtstage und einen guten Start ins Jahr 2015.

Ihre

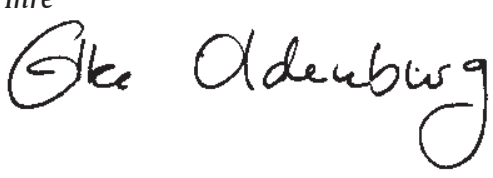

Wie gefällt Ihnen die physiografik? Machen Sie mit bei unserer Umfrage unter bit.ly/Umfrage_physiografik. Als Dankeschön verlosen wir unter allen Teilnehmern zehn Thieme-Buchgutscheine im Wert von 50 Euro. Der QR-Code führt Sie direkt zur Umfrage.

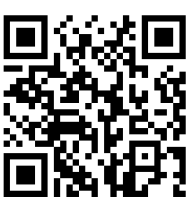

\section{ZU GEWINNEN}

In jeder physiopraxis werden attraktive Gewinne verlost. Möchten Sie einen ergattern, klicken Sie unter www.thieme.de/ physiopraxis auf „Gewinnspiel“.

Und das gibt es in dieser Ausgabe zu gewinnen:
Bücher

1-mal „Rheuma“

3-mal „Alltag in

Amerika"

3-mal „Fettnäpfchen-

führer Australien“

1-mal

„Sportphysiotherapie“ Seite 62

3-mal „Weihnachts-

plätzchen“"
Seite 34

Seite 57

Seite 57

Seite 97 und außerdem ...

2 physiokongress-Karten Seite 97 1 Holzschlitten

Seite 97

1 Authentics Pill

Wärmeflasche

Seite 97

je 1 Naturmoor-Beckenund -Nackenwärmer 3 WellnessÖle mit verschiedenem Duft Seite 97 